\title{
Koperasi Simpan Pinjam Berbasis Web pada Koperasi Subur Surakarta
}

\author{
Agung Nugroho*1, Robby Rachmatullah ${ }^{2}$, Hakim Prabandara ${ }^{3}$ \\ ${ }^{1}$ Program Studi Teknik Komputer; ${ }^{2}$ Program Studi Sistem Informasi; \\ ${ }^{3}$ Program Studi Sistem Informasi \\ ${ }^{123}$ STMIK AUB Surakarta, Indonesia \\ e-mail: *1agung_new@stmik-aub.ac.id, ${ }^{2}$ robby_r@stmik-aub.ac.id, ${ }^{3}$ hakim.bandara@gmail.com
}

\begin{abstract}
Abstrak
Koperasi Pegawai Republik Indonesia Subur salah satu koperasi simpan pinjam yang beranggotakan para pegawai negeri sipil. KPRI Subur berupaya meningkatkan pelayanan yang maksimal kepada para anggota. Dalam perkembanganya KPRI Subur mengalami kendala dalam proses pembuatan laporan, proses pengajuan pinjaman dan pengolahan simpan pinjam. Oleh karna itu KPRI Subur membutuhkan sistem informasi simpan pinjam berbasis web agar permasalahan tersebut dapat diselesaikan dengan baik. Dalam penelitian ini sistem yang dibangun berbasis web menggunakan bahasa pemograman PHP native, dan My SQl sebagai basis data. metode perancangan dengan menggunakan metode waterfall. Metode pengumpulan data dengan metode wawancara, metode observasi dan metode pustaka. Sebagai alat bantu analisis dan perancangan yang digunakan adalah flowchart, DFD (Data Flow Diagram ), dan Entity Relationship Diagram.Sistem yang dibangun memberikan kemudahan bagi pihak KPRI Subur dalam proses pengolahan data sismpan pinjam, pembuatan laporan dan pengajuan pinjaman. Sehingga dengan adanya Sistem Informasi Koperasi Simpan Pinjam Berbasis Web pada Koperasi Subur Surakarta mampu mewujudkan pelayanan yang maksimal kepada anggotanya
\end{abstract}

Kata kunci: Sistem Informasi, Koperasi Simpan Pinjam, KPRI Subur, PHP

\section{PENDAHULUAN}

Perkembangan Sistem informasi adalah kombinasi dari teknologi informasi dan aktivitas orang yang menggunakan teknologi itu untuk mendukung operasi dan manajemen. Dalam arti yang sangat luas, istilah sistem informasi yang sering digunakan merujuk kepada interaksi antara orang, proses algoritmik, data, dan teknologi. Dalam pengertian ini, istilah ini digunakan untuk merujuk tidak hanya pada penggunaan organisasi teknologi informasi dan komunikasi (TIK), tetapi juga untuk cara di mana orang berinteraksi dengan teknologi ini dalam mendukung proses bisnis.

Koperasi adalah organisasi bisnis yang dimiliki dan dioperasikan oleh sekelompok orang demi kepentingan bersama.Dalam pengerjaannya koperasi juga memerlukan sebuah sistem informasi untuk mempermudah dalam melakukan pekerjaannya.Koperasi juga sebagai wadah yang dapat membantu masyarakat terutama masyarakat kecil dan menengah.Koperasi yang menawarkan peminjaman dan penyimpanan uang ini disebut koperasi simpan pinjam.Tujuannya adalah agar supaya masyarakat dapat menabung pada koperasi tersebut sehingga masyarakat dapat merasa tenang dalam menyimpan uangnya selain itu dalam hal peminjaman, masyarakat dapat melakukan peminjaman kepada pihak koperasi dengan bunga yang sangat kecil untuk membangun usaha atau bisnis yang diinginkan.Inilah alasan mengapa

Received November 12, 2018; Revised November 28, 2018; Accepted December 10, 2018 
koperasi sangat memegang peranan penting dalam pertumbuhan ekomomi masyarakat Indonesia.

Salah satu Koperasi Pegawai Republik Indonesia (KPRI) Subur yang ada di Surakarta adalah koperasi simpan pinjam yang beranggotakan para pegawai negeri sipil, dalam perkebangan KPRI Subur sudah menerapkan komputerisai dalam pengolahana data, namun dalam hal pengajuan pinjaman oleh anggota koperasi, serta pengolahan data anggota baru masih konvesional. Meskipun teknologi sudah tersedia, namun koperasi (KPRI) Subur masih mempunyai kesulitan dalam proses pengolahan data Laporan bulan yang tidak tepat waktu dan tidak bisa diakses secara realtime oleh pipinan koperasi, proses pengajuan pinjaman yang menguras waktu dan tenaga, karna anggota harus bolak-balik ke kopreasi hanya untuk pengajuan pinjaman, serta bagian adminitrasi kesulitan dalam mencari data anggota yang bermasalah dalam hal angsuran pinjaman.

Dengan adanya permasalahan tersebut dibuatlah sistem informasi koperasi simpan pinjam yang dapat mengolah data anggota, data simpanan, data pinjaman, laporan bulanan dan laporan tahunan oleh adminitrasi lebih mudah, cepat dan tepat waktu dan menghidari kesalahan dalam hal perhitungan maupun pencatatan.

\section{METODE PENELITIAN}

Metodologi penelitian merupakan langkah-langkah operasional yang digunakan dalam pengembangan sebuah aplikasi sistem informasi koperasi simpan pinjam.

a. Lokasi Penelitian

Koperasi Pegawai Republik Indonesia (KPRI) Subur Surakarta Jl. Kapten Mulyadi No. 219 Kelurahan Pasar Kliwon Kecamatan Pasar Kliwon Kota Surakarta.

b. Metode Observasi

Metode ini, penulis terjuan langsung ke lokasi tempat penelitian di Koperasi Pegawai Republik Indonesia (KPRI) Subur Surakarta Jl. Kapten Mulyadi No. 219 Kelurahan Pasar Kliwon Kecamatan Pasar Kliwon Kota Surakarta. Untuk mencari berbagai informasi tentang sistem yang di terapkan sekarang, serta menanyakan semua data - data anggota, simpanan, pinjaman, struktur organisasi dan informasi berdirinya Koperasi Pegawai Republik Indonesia (KPRI) Subur Surakarta Jl. Kapten Mulyadi No. 219 Kelurahan Pasar Kliwon Kecamatan Pasar Kliwon Kota Surakarta.

c. Metode Wawancara

Menurut Sugiyo (2011), Wawancara digunakan sebagai teknik pengumpulan data apabila peneliti ingin melakukan studi pendahuluan untuk menemukan permasalahaan yang harus diteliti, dan juga apabila peneliti ingin mengetahui hal-hal dari respoden yang lebih mendalam dan jumlah respodennya sedikit. Teknik pengumpulan data dengan wawancara dapat dilakukan secara terstruktur maupun tidak terstruktur dan dapat dilakukan melalui tahap.

Maka penulis mewancarai secara langsung semua pihak - pihak yang berkait di KPRI Subur Surakarta, seperti Pimpinan Koperasi, Anggota, Karyawan, Admin. Wawancara tersebut berisikan tentang seputar akademik di KPRI Subur Surakarta.

d. Metode Pustaka

Menurut Prastowo Pohan (2012), bertujuan mengumpulkan data dan informasi ilmiah, berupa teori-teori, metode, atau pendekatan yang pernah berkembang dan telah di dokumentasikan dalam bentuk buku, jurnal, naskah, catatan, rekaman sejarah, dokumendokumen, dan lain-lain yang terdapat di perpustakaan.

e. Metode Pengembangan Sistem

Pengembangan mengunakan metode wartefal salah satunya model air terjun yang penulis gunakan yaitu yang disebut model sekuensial atau terurut dimulai dari perancangan, analisa, disen, pengkodean, pengujian dan pemeliharaan. Kemudian model air terjun adalah untuk membantu mengatasi kerumitan yang terjadi akibat proyek - proyek pengembangan perangkat lunak, sebuah air terjun untuk merinci apa yang seharusnya perangkat lunak 
lakukan (mengumpulkan dan menentukan kebutuhan sistem) sebelum sistem dikembangkan. Kemudian model ini memungkinkan pemecahan misi pengembangan yang rumit menjadi beberapa langkah logis yang pada akhirnya akan menjadi produk akhir yang siap pakai. ( SimarmataJanner, 2010).

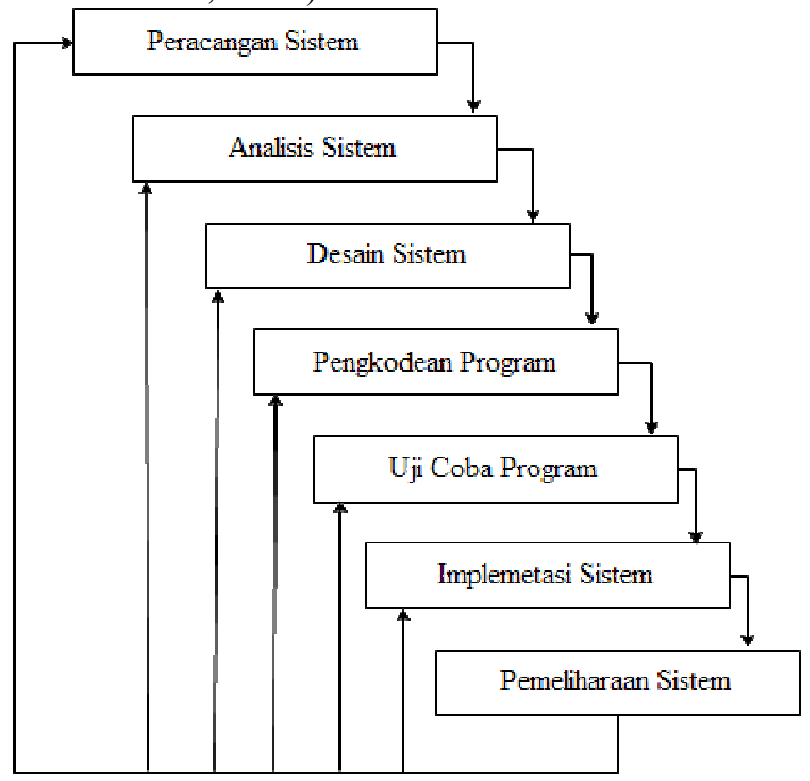

Gambar 1 Metode Waterfall

Penjelasan gambar 1 diagram model waterfall :

a. Perancangan Sistem

Perancangan sistem informasi merupakan pengembangan sistem baru dari sistem lama yang ada, dimana masalah-masalah yang terjadi pada sistem lama diharapkan sudah sudah teratasi pada sistem yang baru.

b. Analisis Sistem

Langkah ini merupakan analisa terhadap kebutuhan sistem. Pengumpulan data dalam tahap ini bisa melakukan sebuah penelitian, wawancara atau studi literatur. Sistem analisis akan menggali informasi sebanyak - bayaknya dari user sehingga akan tercipta sebuah sistem komputer yang bisa melakukan tugas - tugas yang diinginkan oleh user reguirment atau bisa dikatakan sebagai data yang berhubungan dengan keinginan user dalam pembuatan sistem. Dokumen ini yang akan menjadi acuan sistem analisi untuk menerjemahkan kedalam bahasa pemograman.

c. Desain Sistem

Proses multi langkah yang fokus pada desain pembuatan program perangkat lunak termasuk struktur data, arsitektur perangkat lunak, refresentasi antarmuka, dan procedure pengodean.

d. Pengkodean Program

Penulisan kode program atau coding merupakan penerjemah desain dalam bahasa yang bisa dikenal oleh komputer. Dilakukan oleh seorang programmer yang akan meterjemahkan transaksi yang diminta oleh user. Tahapan ini yang merupakan gambaran nyata dalam mengerjakan suatu sistem. Dalam artian penggunaan komputer akan dimaksimalkan dalam tahapan ini.

e. Pengujian

Pengujian ini fokus pada perangkat lunak secara dari segi fungsional dan memastikan bahwa semua sudah diuji sehingga didapatkan kekurangan dan kelemahan sistem yang kemudian dilakukan pengajian ulang dan perbaikan terhadap aplikasi menjadi lebih baik dan sempurna.

f. Pemeliharaan

GO INFOTECH: JURNAL ILMIAH STMIK AUB Vol. 24, No. 2, Desember 2018 : $74-80$ 
Tahap pemeliharaan ini tidak menutup kemungkinan sebuah perangkat lunak mengalami perubahan ketika sudah dikirim ke user, perubahan biasa terjadi karena adanya kesalahan yang muncul dan tidak terdetek di lingkungan baru.

\section{HASIL DAN PEMBAHASAN}

\subsection{Pembahasan}

a. Form Login

Form login digunakan untuk masuk ke dalam aplikasi atau operasi selanjutnya. Apabila login berhasil, maka akan masuk ke dalam halaman menu utama, tetapi apabila login tidak berhasil maka akan ada peringatan bahwa login yang dilakukan salah dan akan menuju form login. Di dalam form login akan mengarahkan pengguna ke dalam salah satu halaman menu utama berdasarkan level pengguna.

b. Form Menu Utama Admin

Form Menu utama admin adalah form yang ditampilkan pada menu utama sistem dengan level pengguna sebagai admin. Pada form ini terdapat beberapa pilihan toolbar dan menu yaitu master data, transaksi, laporan dan pengaturan. Setiap menu akan terhubung dengan form-form lain yang sesuai dengan form yang dipanggil. Pada menu master data terdapat sub menu master form data user, form jenis simpanan dan form jenis pinjaman. Sedangkan pada menu transaksi terdapat sub menu simpanan, pinjaman dan angsuran. Pada menu laporan terdapat sub menu laporan simpanan, laporan pinjaman, laporan bayar pinjam. Pada menu pengaturan teradapat sub menu profile dan logout.

\section{c. Form Data User}

Form data user adalah salah satu dari sub menu master data pada menu utama admin. Form data user ini digunakan untuk memasukan data mengenai user yang nantinya mengoperasikan aplikasi. Untuk kode admin sudah diberlakukan otomatisasi kode sehingga pada saat masuk kedalam form administrator ini kode admin akan mucul secara otomatis.

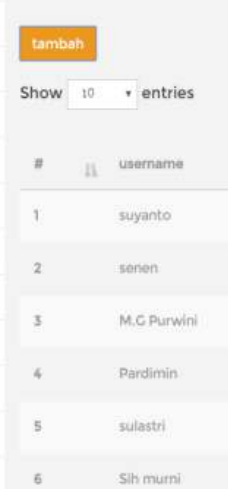

d. Form Data Jenis Simpan

Form data jenis simpan adalah salah satu dari sub menu master data pada menu utama admin. Pada form data jenis simpan terdapat pilihan menambah, mengedit atau mengubah dan menghapus data jenis simpan. Selain itu pada form data jenis simpan juga terdapat opsi pencarian data jenis simpan.

e. Form Data Jenis pinjam

Form data jenis pinjam adalah salah satu dari sub menu master data pada menu utama admin. Pada form data jenis pinjam terdapat pilihan menambah, mengedit atau mengubah dan menghapus data jenis pinjam. Selain itu pada form data jenis pinjam juga terdapat opsi pencarian data jenis pinjam.

f. Form Data Pinjam 
Form data pinjam adalah salah satu dari sub menu master data pada menu utama admin. Pada form data pinjam terdapat pilihan menambah, mengedit atau mengubah dan menghapus data pinjam. Selain itu pada form data pinjam juga terdapat opsi pencarian data pinjam.

g. Form Data Simpan

Form data simpan adalah salah satu dari sub menu master data pada menu utama admin. Pada form data simpan terdapat pilihan menambah, mengedit atau mengubah dan menghapus data jenis simpan. Selain itu pada form data simpan juga terdapat opsi pencarian data simpan.

h. Form Data Angsuran

Form data angsuran adalah salah satu dari sub menu master data pada menu utama admin. Pada form data angsuran terdapat pilihan menambah, mengedit atau mengubah dan menghapus data angsuran. Selain itu pada form data angsuran juga terdapat opsi pencarian data angsuran.

i. Form Laporan Arus Kas

Form laporan Arus kas adalah salah satu dari sub menu laporan pada menu utama admin. Pada form laporan arus kas dapat menampilkan data laporan data arus kas pada waktu periode tertentu.

j. $\quad$ Laporan Sisa Pinjman Anggota

Form laporan sisa pinjaman anggota adalah salah satu dari sub menu laporan pada menu utama admin. Pada form laporan arus kas dapat menampilkan data laporan sisa pinjaman anggota.

k. Laporan Neraca

Form laporan neraca adalah salah satu dari sub menu laporan pada menu utama admin. Pada form laporan neraca dapat menampilkan data nereca berdasarkan periode tertentu.

1. Laporan Simpanan Anggota

Form laporan simpanan anggota adalah salah satu dari sub menu laporan pada menu utama admin. Pada form laporan simpanan anggota dapat menampilkan data simpanan anggota berdasarkan periode tertentu.

\subsection{Pemeliharan Sistem}

Tahap terakhir dari proses penerapan sistem merupakan tahap pemeliharan yang harus dilakukan selama sistem masih berjalan dan masih digunakan untuk melakukan transaksi. Selama masih digunakan sistem maka pemeliharan akan terus dilakukan secara periodik akan ditinjau. Perubahan terhadap sistem akan dilakukan apabila muncul masalah atau ada kebutuhan baru terhadap sistem yang digunakan untuk menyesuaikan dengan perkembangan zaman, Selanjutnya, instansi terkait akan menggunakan sistem yang telah diperbaiki tersebut. Dengan adanya pemeliharan tersebut maka sistem dapat di kontrol, sehingga ketika dioprasikan tidak akan mengalami hambatan dan menemui masalah. Berikut ini adalah langkah - langkah pemeliharan sistem terdiri dari:

a. Pemeliharan Korektif

Pemeliharan korektif adalah sebagian pemeliharan sistem yang tidak begitu tinggi nilainya dan lebih membebani, karna pemeliharan ini mengkoreksi kesalahan-kesalahan yang ditemukan pada saat sistem berjalan. Berikut tahap - tahap pemeliharan korektif:

1) Deteksi:

a. Cek fungsi.

b. Cek kinerja.

c. Bandingkan dengan spesifikasi alat atau sistem.

2) Menentukan lokasi

a. Cek fungsi tiap blok (bagian dari sistem).

b. Cek komponen pada blok yang tidak bekerja dengan baik.

3) Perbaikan.

Perbaikan ganti komponen yang rusak dengan yang baru.

GO INFOTECH: JURNAL ILMIAH STMIK AUB Vol. 24, No. 2, Desember 2018 : $74-80$ 
a. Pemeliharan Adaptif

Pemeliharan adaptif dilakukan untuk menyesuaikan perubahan dalam lingkungan data atau pemprosesan dan memenuhi persyaratan pemakai baru.

b. Pemeliharan Prepektif

Pemeliharan penyempurnaan mempertinggi cara kerja atau maintainabilitas (kemampuan untuk dipelihara).

c. Pemeliharan preventif

Pemeliharan preventif terdiri atas inspeksi periodik dan pemeriksaan sistem untuk mengungkap dan mengantisipasi permasalahan.

\section{KESIMPULAN}

Telah dirancang dan dibangun Sistem Informasi Koperasi Simpan Pinjam Berbasis Web pada Koperasi Subur Surakarta. Berdasarkan hasil penelitian yang telah penulis lakukan, kesimpulan yang didapat adalah sebagai berikut: Sistem yang berjalan pada Koperasi Subur Surakarta didapatkan permasalahan yang dihadapi dalam proses pengolahan data laporan simpanan pinjaman dimana sering terjadinya keterlambatan pembuatan laporan untuk pimpinan. Selain hal tersebut permasalahan mengenai mengenai perhitungan dan pencatatan yang sering kesalahan. Hal ini berdampak pada lambatnya proses untuk memperoleh informasi mengenai data simpan pinjam bagi administrasi. Sistem Informasi Koperasi Simpan Pinjam Berbasis Web pada Koperasi Subur Surakarta membantu bagian anggota dalam melakukan pengajuan pinjaman sehingga pelayanan proses pengajuan pinjaman anggota dapat menjadi lebih cepat dari sebelumnya. Selain itu Sistem Informasi Koperasi Simpan Pinjam Berbasis Web pada Koperasi Subur Surakarta juga membantu bagian ketua dalam memperoleh laporan data secara realtime untuk menujang kinerja ketua dalam proses persetujuan pengajuan pinjaman. Dengan adanya Sistem Informasi Koperasi Simpan Pinjam Berbasis Web pada Koperasi Subur Surakarta dapat mewujudkan visinya yaitu menjadi koperasi yang mampu memberikan pelayanan yang maksimal kepada anggotanya.

\section{SARAN}

Berdasarkan pada kesimpulan di atas, maka penulis akan memberikan beberapa saran sebagai berikut: bagian pendaftaran anggota dapat signup dengan akun aplikasi pihak ketiga atau media sosilan. Dapat dikembangkan pada bagian transaksi yang terintregasi dengan bank. Untuk penelitian selanjutnya sistem bisa dikembangkan lagi untuk melengkapi mengenai manajemen keuangannya sehingga fitur sistem lebih lengkap. Mengembangkan fitur pemberitahuan otomatis dan berkala tiap bulan mengenai data harta simpan pinjam anggota menggunakan fitur email.

\section{DAFTAR PUSTAKA}

[1] Aditama, 2013. Apache, MySQL, PHP dan PHPMyAdmin. Xampp dapat diperoleh pada situs apachefriend.org.

[2] Afrianto, 2014. Informasi Kopserasi Berbasis Web Pada kopserasi Sejahtera Besama Bandung.

[3] Al Fatta, 2007 Analisis Dan Perancangan System Informasi Untuk Keunggulan Perusahaan Dan Organisasi Kelas Dunia. Yogyakarta: Andi offset-STMIK AMIKOM.

[4] Arief, 2011. PHP (HypertextPrepocessor) bahasa server-side-scripting yang menyatu dengan HTML

[5] Daruwira P, 2009. Teori Dasar Sistem Informasi Ilmu Komputer,Yogyakarta

[6] Dinas Koperasi, 2009. Kota Bandung. Buku Pintar KUKM Kota Bandung 
[7] Hall, 2007. Sistem informasi Akuntansi. Jakarta : Salemba Empat.

[8] Heni, 2009. Sistem Informasi Simpan Pinjam di Dinas Koperasi UKM dan Perindag Kota Bandung.

[9] http://getbootstrap.com/. UI Framework (Bootstrap 3.3.5). components, JavaScript plugins, typography, formcontrols, dan juga sebuah webbased.

[10] Hutahean, 2014. KONSEP SISTEM INFORMASI. Yogyakarta: DEEPUBLISH

[11] Ika, 2017 Sistem Informasi Simpan Pinjam Gotong Royong Karanganyar. STMIK AUB Surakarta: Sistem Informasi.

[12] Jogiyanto, 2005. Analisis dan Desain Sistem Informasi : Pendekatan Terstruktur Teori dan Praktik Aplikasi Bisnis. Yogyakarta: Andi Offset

[13] Jogiyanto, 2013. Metode Pengembangan Sistem Warterfall.2013. Yogyakarta: Andi Offset

[14] Mansur, 2011. Pengertian Domai. Buku TKJ kelas XII.

[15] Nugroho, Bunafit, 2008. Membangun Sistem Informasi Berbasis WEB dengan PHP dan MySQL. Yogyakarta: Gava Media

[16] Rosa A.S M.Shalahudin. 2011. Modul pembelajaran rekayasa perangkat lunak(terstruktur dan berorientasi obyek ). Bandung: modula.

[17] Yakub, 2012. "Pengantar Sistem Informasi", Yogyakarta: Graha Ilmu.

[18] Yuhefizar, 2012. WWW (Word Wide Web) dan Http (Hypertext Tranfer Protocol). 